\title{
Identification and Prioritizing Influential Merchandising Variables on Customer Purchase Behavior, Case Study:Hyper Star Chain Supermarket
}

\author{
Somayeh Salahshouri Ardestani \\ Master of Business Administration, Jawaharlal Nehru Technological University, Hyd-India \\ s.salahshour@gmail.com \\ Iman Salahshouri Ardestani \\ Master of Financial Engineering, Islamic Azad University of Dehaghan - Iran \\ imansalahshour@yahoo.com
}

\section{Doi:10.5901/mjss.2016.v7n3s2p48}

\section{Abstract}

\begin{abstract}
The purpose of this research was evaluation of the effectiveness of merchandising variables on customer purchase behavior. This research was performed by survey and by distribution of questionnaire. The results of this research showed that after extraction of 57 variables from literature related to merchandising, they were distributed among ten experts and after moderation of the variables to 37, they were distributed among 250 customers in Hyper Star Chain Supermarkets. Statistical analysis included descriptive values and inferential statistics for data analysis. After data collection by questionnaire, they were analyzed using the SPSS software. Considering the results of the research, merchandising variables influential on customer purchase behavior were identified and ultimately ranking of influential merchandising constituents was performed. Results of the Friedman test showed that at a 0/95 confidence level, significant difference exists between ranked mean effectiveness of influential merchandising factors on customer purchase behavior at Hyper Star. In fact, it can be stated that advertisement strategies in merchandising had the highest effect on customer purchase behavior. After this were behavioral variables, technical strategy and ultimately environmental strategy in decreasing order of effectiveness on customer purchase behavior.
\end{abstract}

Keywords: Marketing, Merchandising, Purchase Behavior, Hyper Star

\section{Introduction}

Today's world is a world of rapid evolutions in all dimensions of trade, industry, agriculture and services. World trade and expansion of activity domain of companies and organizations to internal markets in the arena of competition has forced marketing to be more than ever point of attention (Davar, 1996). Marketing development is not just limited to increased income by way of sales and services, but also has a more important role as a growth strategy and even in economic advancement in the domain of word of mouth (Forouzanda, 2002).

Therefore, success in marketing and realization of strong presence in the market arena with use of scientific methods of market management and formulation of marketing strategies and having an appropriate and efficient marketing mix with conditions of the goal product market is among necessities (Parizi, 2010). On the one hand, every product has its own special characteristics which need to be introduced to consumers in away to create motivation and trust. Merchandising helps show all these characteristics to the customer and demonstrates the real image of the commodity. The merchandiser with help of market arrangement and architecture creates a sense in the consumer that lead to his or her commitment to the market and products. If this matter is not taken into consideration, we will witness indifference of customers towards products and the customer will think all products are similar and will not differentiate between them. This important issue can be seen in agencies that use various methods for sale of their products and services. Selection of any of these methods depends on conditions governing over the agency and conditions dominating over products or services. Among various marketing and retailing methods, merchandising is a prevalent and applicable one. Sale by way of merchandising leaves a good memory in the minds of buyers. These markets are active and lively communication bridges between the agency and customers (or the target market). Considering the existing conditions in the business environment of Iran, use of this method is very effective. The culture dominant in Iran also has great coordination with application of this method (Nielsen, 2013). One of the important issues attended to in merchandising is encouragement of customers towards better and increased buy where this important task itself needs taking advantage of 
merchandising variables. Therefore, this research will evaluate the topic of what variables are effective on customer purchase? Which variable of merchandising do customers show increased interest in? What tasks can help enhance merchandising?

\section{Theoretical Statement of the Research}

\subsection{Merchandising}

Merchandising is a method that shows commodities in markets to customers (Canada Center for Business Services, 2004). Merchandising is a language or tool for encouraging customers to shop which is used by small retailers for establishment of communications with target customers (Ailawadi, 2006). Therefore, merchandising is involved with all processes of selection, use, refraining from products and services, experiences and ideas by individuals, groups and organizations for satisfaction of needs and also evaluation of effects of these processes on the customer and society (Amstrong, 2007). In simpler words, merchandising is study of how individuals shop, what they shop and why they shop? (Robinson, 2001)

\subsection{Effective marketing factors on customer purchase behavior}

\section{Advertisement:}

The constituent of advertisement in this research includes variables such as packaging, arrangement, product situation, discounts, product design, advertising strategies, space allocation and cataloguing.

Behavioral:

The behavioral constituent includes 7 variables of background color, size, lighting, emotional and cognitive reaction, intention to buy, product, visual perception, desire.

Technical:

The technical constituent includes 7 variables of presentation of new product, attraction and transfer of message, creation of desire in the customer, profit, expectation, customer loyalty, goal groups, and filling up the room.

Environmental:

The environmental constituent includes 7 variables of attraction, geographic location, visual stimulants, regional differences, exhibition window, product positioning, and weather.

\subsection{Customer behavior}

Customer behavior includes various psychological and social processes that exist before and after activities related to purchase and use. They are stages a buyer goes thought to decide what kind of products and services to purchase. Therefore, it includes physical, emotional and mental activities people do at time of selection, purchase, use and discarding merchandise and services to satisfy his or her needs and wishes (Haans, 2011).

\subsection{Customer purchase decision making process}

Experts believe that the process of purchase begins with identification of need. After a need is identified, consumers seek and investigate information about small retailers/products that may satisfy their need. After collection of information, they evaluate choices and make decisions. After buy, some forms of post purchase emotions/behaviors will exist. The amount of time spent during each stage of the process of buy differs based on the nature of purchase.

When purchase involves high risk, the consumer spends more time searching for information and evaluating. Such decisions to buy are complex and are called highly mentally involved and regarding habitual shopping or daily shopping, the process of decision making is almost simple with low mental involvement, such that no formal process of search for information or evaluation occurs and consumers rely on their previous experience (Van Heerde, 2003).

\section{Method of Research}

This research was applied and method used was descriptive analytic that evaluated real data and ranked choices based on logical and mathematical analysis. Statistical population of the research included all customers that shop at the Hyper Star market. Therefore, in this research sample selection was performed by randomization. Among shoppers at the Hyper 
Star market, randomly 250 individuals were selected and questionnaires were distributed among them and were analyzed.

Overall, the research instrument was questionnaire reviewed by experts. A total of 57 questions were designed and after questionnaire moderation, 37 items remained. A 5-point Likert scale was used for scoring. Since the Cronbach's alpha for the questionnaire was equal to 0/895, the questionnaire reliability was confirmed. Also, since the KMO index (0/883) was equal and higher that 0/6, the data was appropriate for factor analysis. In this research, factor analysis and ttest were used with the help of SPSS 20 software.

\section{Research Hypotheses}

1. Advertisement and variables related to it have direct and meaningful correlation with purchase behavior.

2. The behavioral constituent and variables related to it have direct and meaningful correlation with purchase behavior.

3. The technical constituent and variables related to it have direct and meaningful correlation with purchase behavior.

4. The environmental constituent and variables related to it have direct and meaningful correlation with purchase behavior.

\section{Research Results}

\subsection{Identification of effective constituents of merchandising on customer purchase behavior}

For identification of these constituents, initially 56 constituent were extracted from relevant articles and after evaluation by 10 experts, 29 indices related to merchandising with consideration of their skewness and coefficient of sensitivity were selected which are described below. As a result, the constituents of merchandising effective on purchase behavior of buyers at the Hyper Star market were prepared as follows:

Table (1). Table of Influential indices of merchandising

\begin{tabular}{|c|c|c|c|c|c|}
\hline Index & Index & Factor load & Special value & Variance & Cumulative variance \\
\hline \multirow{8}{*}{ Advertisement } & Packaging & $2 / 494$ & $2 / 129$ & $8 / 908$ & $31 / 657$ \\
\hline & Arrangement & 2/219 & & & \\
\hline & Product positioning & 2/187 & & & \\
\hline & \begin{tabular}{|l|} 
Discounts \\
\end{tabular} & $1 / 930$ & & & \\
\hline & Product design & $1 / 907$ & & & \\
\hline & Advertisement strategies & $1 / 274$ & & & \\
\hline & Space allocation & $1 / 024$ & & & \\
\hline & Cataloguing & $0 / 932$ & & & \\
\hline \multirow{8}{*}{ Behavioral } & & & & & \\
\hline & Background color & $2 / 245$ & $2 / 601$ & $7 / 128$ & $30 / 447$ \\
\hline & Size & $2 / 012$ & & & \\
\hline & Lighting & $2 / 001$ & & & \\
\hline & Cognitive and emotional reaction & $1 / 985$ & & & \\
\hline & Intention to buy product & $1 / 012$ & & & \\
\hline & Visual perception & 0/985 & & & \\
\hline & Desire & $0 / 877$ & & & \\
\hline \multirow{7}{*}{ Technical } & Presentation of new product & $2 / 174$ & $2 / 719$ & $11 / 327$ & $22 / 749$ \\
\hline & Attraction and transfer of massage & $2 / 092$ & & & \\
\hline & Creation of interest in the customer & $1 / 987$ & & & \\
\hline & Expected profit & $1 / 349$ & & & \\
\hline & Customer loyalty & $1 / 102$ & & & \\
\hline & Target groups & 0/971 & & & \\
\hline & Filling the room up & $0 / 808$ & & & \\
\hline
\end{tabular}




\begin{tabular}{|c|l|l|l|l|l|}
\hline \multirow{5}{*}{ Environmental } & Attraction & $1 / 710$ & $2 / 741$ & $11 / 422$ & $11 / 422$ \\
\cline { 2 - 6 } & Geographical location & $1 / 695$ & & & \\
\cline { 2 - 6 } & Visual stimulants & $1 / 006$ & & & \\
\cline { 2 - 6 } & Regional differences & $0 / 985$ & & & \\
\cline { 2 - 6 } & Exhibition window & $0 / 864$ & & & \\
\cline { 2 - 6 } & Product localization & $0 / 517$ & & & \\
\cline { 2 - 6 } & Weather & $0 / 745$ & & & \\
\hline
\end{tabular}

\subsection{Test of First Hypothesis}

Advertisement factors have direct and meaningful correlation with purchase behavior.

Considering Table (3), the test statistic of 12/06 is larger than 1/96, lower and upper limits of mean have positive signs and significance level is equal to 0/000 which is less than the 0/05 level and it can be concluded that the research hypothesis is confirmed. Also, considering that mean opinions is $4 / 25$ which is higher than the assumed mean of 3 , this means that Hyper Star market buyers have considered the correlation between these two indices to be high.

Table (2). Statistics related to hypothesis one

\begin{tabular}{|c|c|c|c|c|}
\hline Sample size & Mean & Significance level & Standard deviation & Mean standard error \\
\hline 250 & $4 / 25$ & $0 / 000$ & $0 / 75$ & $0 / 05$ \\
\hline
\end{tabular}

Table (3). T-test statistic related to hypothesis one

\begin{tabular}{|c|c|c|c|c|c|}
\hline Value for test statistic & Degrees of freedom & Significance level & Mean difference & \multicolumn{3}{|c|}{95 confidence interval for the mean } \\
\cline { 5 - 6 } & & & & Upper level & Lower level \\
\hline $12 / 06$ & 249 & $0 / 000$ & $0 / 58$ & $0 / 67$ & $0 / 48$ \\
\hline
\end{tabular}

\subsection{Test of Second Hypothesis}

Behavioral factors have direct and meaningful correlation with purchase behavior.

Considering Table (5), the test statistic of 10/02 is larger than 1/96, lower and upper limits of mean have positive signs and significance level is equal to 0/000 which is less than the 0/05 level and it can be concluded that the research hypothesis is confirmed. Also, considering that mean opinions is $3 / 58$ which is higher than the assumed mean of 3 , this means that Hyper Star market buyers have considered the correlation between these two indices to be high.

Table (4). Statistics related to hypothesis two

\begin{tabular}{|c|c|c|c|}
\hline Sample size & Mean & Standard deviation & Mean standard error \\
\hline 250 & $3 / 58$ & $0 / 80$ & $0 / 05$ \\
\hline
\end{tabular}

Table (5). T-test statistic related to hypothesis two

\begin{tabular}{|c|c|c|c|c|c|}
\hline Value for test statistic & Degrees of freedom & Significance level & Mean difference & \multicolumn{3}{|c|}{95 confidence interval for the mean } \\
\cline { 5 - 6 } & & & & Upper level & Lower level \\
\hline $10 / 02$ & 249 & $0 / 000$ & $0 / 03$ & $0 / 57$ & $0 / 32$ \\
\hline
\end{tabular}

\subsection{Test of Third Hypothesis}

Technical factors have direct and meaningful correlation with purchase behavior.

Considering Table (7), the test statistic of 9/382 is larger than 1/96, lower and upper limits of mean have positive signs and significance level is equal to 0/000 which is less than the 0/05 level and it can be concluded that the research hypothesis is confirmed. Also, considering that mean opinions is $3 / 30$ which is higher than the assumed mean of 3 , this means that Hyper Star market buyers have considered the correlation between these two indices to be high. 
Table (6). Statistics related to hypothesis three

\begin{tabular}{|c|c|c|c|}
\hline Sample size & Mean & Standard deviation & Mean standard error \\
\hline 250 & $3 / 30$ & $0 / 67$ & $0 / 05$ \\
\hline
\end{tabular}

Table (7). T-test statistic related to hypothesis three

\begin{tabular}{|c|c|c|c|c|c|}
\hline Value for test statistic & Degrees of freedom & Significance level & Mean difference & \multicolumn{3}{|c|}{95 confidence interval for the mean } \\
\cline { 5 - 6 } & & & & Upper level & Lower level \\
\hline $9 / 38$ & 249 & $0 / 000$ & $0 / 40$ & $0 / 49$ & $0 / 32$ \\
\hline
\end{tabular}

\subsection{Test of Fourth Hypothesis}

Environmental factors have direct and meaningful correlation with purchase behavior.

Considering Table (9), the test statistic of $8 / 57$ is larger than $1 / 96$, lower and upper limits of mean have positive signs and significance level is equal to 0/000 which is less than the 0/05 level and it can be concluded that the research hypothesis is confirmed. Also, considering that mean opinions is $3 / 10$ which is higher than the assumed mean of 3 , this means that Hyper Star market buyers have considered the correlation between these two indices to be high.

Table (8). Statistics related to hypothesis four

\begin{tabular}{|c|c|c|c|}
\hline Sample size & Mean & Standard deviation & Mean standard error \\
\hline 250 & $3 / 10$ & $0 / 52$ & $0 / 05$ \\
\hline
\end{tabular}

Table (9). T-test statistic related to hypothesis four

\begin{tabular}{|c|c|c|c|c|c|}
\hline Value for test statistic & Degrees of freedom & Significance level & Mean difference & \multicolumn{3}{|c|}{95 confidence interval for the mean } \\
\cline { 5 - 6 } & & & & Upper level & Lower level \\
\hline $8 / 57$ & 249 & $0 / 000$ & $0 / 47$ & $0 / 51$ & $0 / 31$ \\
\hline
\end{tabular}

\section{Conclusion/Discussion}

Merchandising is a method in markets that shows products to customers. Therefore, it constitutes of all helps and services that advertising agencies or media place in the hands of merchandise owners to exhibit, supply and sell the product optimally and gain success. As a result, merchandising can have significant influence on customer purchase behavior. In this research, considering the importance of merchandising, we endeavored to identify influential merchandising indices on customer buy behavior where initially 56 constituents were extracted and after evaluation by 10 experts, 29 relevant to merchandising were determined in 4 total factors of advertisement, behavioral, technical and environmental. After performing student t-test, it was concluded that the factors in order of decreasing effectiveness were advertisement, behavioral, technical and environmental. In relation with this research, in an article titled "Role of tourism marketing mix in attraction of tourists" by Mr Ebrahimi in 2010, it has been stated that in the present highly competitive market, the success of every business is dependent on numerous factors. Markets for products and services have become tremendously evolved and complex. Customer needs have changed and their expectations have arisen. For sustenance in such competitive arena, companies need to pay more and more attention to factors that affect customer purchase decision and ultimately their sales. The results of a research in Canada Business Services Center in 2004 have shown that two thirds of product purchase decisions are exactly made at the shopping location. Merchandising is among factors that influences customer purchase decision and ultimately sale by companies.

Merchandising is collection of methods for exhibition of products existing in markets to customers. In this applied research, we evaluated the influence of merchandising implementation on daily used product sale and their retail in selected branches of a large chain supermarket in the city of Tehran. Additionally, in an article titled "Evaluation of effect of merchandising on customer purchase behavior for daily used products" by Mr Mirahmad Amirshahi in 2006, it was noted that success of every business in the present highly competitive market is dependent on various factors. Markets for merchandise and services have tremendously become evolved and complex. Customer needs changed and their expectations have arisen such that for sustenance in this area, more and more attention needs to be devoted to factors 
that influence customer purchase. One of the factors influential on customer purchase decision is merchandising.

Merchandising is a collection of methods that by their help, commodities in markets are demonstrated to customers. Therefore, companies can with implementation of merchandising factors be influential on purchase decision and perception of customers and as a result their return for their products and ultimately their loyalty. The results of this research while emphasizing the significant influence of merchandising factors on customer purchase decision for daily consumed products, confirms that the effect of «shelf cleanness» has been higher than other merchandising factors. In the following, with consideration of results obtained from this research, in line with promotion of role of merchandising in purchase by customers of the Hyper Star supermarket and removal of existing barriers and challenges, by differentiation based on each hypothesis, suggestions and strategies are recommended:

Hypothesis One

$\checkmark$ Making customers aware of advantages of purchase from markets that make use of merchandising.

$\checkmark$ Persistent customer opinion evaluation regarding method of merchandising.

$\checkmark$ Acquisition of strategic decisions for simplification of tasks and use of merchandising by senior managers.

$\checkmark$ Creation of rules and regulations for facilitation of use of merchandising (regarding supermarket taxes).

$\checkmark$ Promotion of quality of products for customers to gain confidence that there is no need to evaluate their quality.

$\checkmark$ Broadcasting of TV advertisement and educational programs in prime time hours.

$\checkmark$ Sending general messages that attract customer attention.

$\checkmark$ Production and broadcasting of TV and radio programs for making customer and benefactors aware of advantages of merchandising.

Hypothesis Two

$\checkmark$ Management of customer complaints in an efficient and effective manner, because slow and inaccurate approach towards complaints presented by customers has negative effect on merchandising.

$\checkmark$ Determination of a specific and particular section for addressing customer opinions and complaints.

Hypothesis Three

$\checkmark$ Expansion of correct and effective culture of merchandising utilization by cultural preparation and contexting.

Hypothesis Four

$\checkmark$ Quantitative and qualitative development of human resources specialized in merchandising.

$\checkmark$ Formulation and preparation of educational texts and notes for familiarizing employees with merchandising concepts.

$\checkmark$ Absorption of innovative and creative human resources with the purpose of creating the necessary context.

$\checkmark$ Utilization of specialized managers in merchandising.

$\checkmark$ Utilization of latest up to date technology for prevention of occurrence of any disorder such as abruption of communication in the system for easier shopping.

\section{References}

[In Persian]

Amirshahi, Mir Ahmad; Jonaii, Massoumeh (2006). Evaluation of effect of merchandising on customer purchase decision in daily used products. Collection of Articles Presented in International Business Management Conference, Razi Congress Salon, Tehran.

Cutler, Philip and Armstrong (1985). Marketing principles, fourth edition (Translation: Forouzandeh, Bahman ,2002). Atroput Publications.

Davar, Abdolhamid; Ebrahimi, Venus; Rousta, Ahmad (1996). Marketing research. Samt Publications.

Ebrahimi, Abdolhamid (2006). Tourism marketing mix in increased tourist attraction. Management Studies, p110.

Parizi and Sassangohar (2010). Organization and Management for theory to practice.

Robinson and Piers (1985). Strategic management planning (Translation: Dr Sohrab Khalili Shourini, 2001). Yadvareh Ketab Publications.

[In English]

Ailawadi, K.L., Harlam, B.A., César, J., Trounce, D., 2006. Pro- motion profitability for a retailer the role of promotion, brand, category, and store characteristics. J. Marketing Res. 43,518---535.

Amstrong, G., Kotler, P., 2007. Marketing An Introduction. Pearson

Haans, H., Gijsbrechts, E., 2011. One-deal-fits-all? On category sales promotion effectiveness in smaller versus larger supermar- kets. J. Retailing 87 (4), 427---443.

Nielsen AC, 2013. Anuario Nielsen. http//es.nielsen.com/ news/20130213.shtml

Van Heerde, H.J., Gupta, S., Wittink, D.R., 2003. Is $75 \%$ of the sales promotion bump due to brand switching? No, only $33 \%$ is. J. Marketing Res. 40, 481---491. 